\title{
Nocturnal blood pressure rise as a predictor of cognitive impairment among the elderly: a retrospective cohort study
}

\author{
Yunli Xing ${ }^{1}$, Ying Sun ${ }^{1}$, Shan Wang ${ }^{1}$, Feng Feng ${ }^{1}$, Deqiang Zhang ${ }^{1}$ and Hongwei $\mathrm{Li}^{1,2^{*}}$ (D)
}

\begin{abstract}
Background: This study investigated the different blood pressure patterns that were evaluated by ambulatory blood pressure monitoring (ABPM) among elderly patients and explored the effect of pressure patterns on cognitive impairment and mortality.
\end{abstract}

Methods: A total of 305 elderly participants aged $\geq 65$ years were divided into the cognitive impairment group $(\mathrm{Cl}$, $n=130)$ and the non-cognitive impairment group $(\mathrm{NCl}, n=175)$ according to the MMSE score. All participants underwent ABPM to evaluate possible hypertensive disorder and cerebral MRI for the evaluation of cerebral small vessel disease. Follow-up was performed by telephone or medical records. The primary outcome was all-cause mortality. Secondary endpoints were major adverse cardiac and cerebrovascular events (MACCE).

Results: Among 305 participants, 130 (42.6\%) were identified with cognitive impairment (Cl), with average systolic blood pressure (BP) of $127 \mathrm{mmHg}$ and diastolic BP of $66 \mathrm{mmHg}$. According to ABPM, only $13.1 \%$ had a dipper pattern, $45.6 \%$ had a nocturnal BP rise, while $41.3 \%$ had a non-dipper pattern. Compared with NCl patients, the Cl group had significantly higher night-time systolic BP (130.0 \pm 18.2 vs. $123.9 \pm 15.1, p=0.011)$, and more participants had nocturnal BP rise (52.3\% vs. $40.6 \%, p=0.042)$. Nocturnal BP rise was associated with greater white matter hyperintensities $(\mathrm{WMH})(p=0.013)$. After 2.03 years of follow-up, there were 35 all-cause deaths and 33 cases of major adverse cardiac and cerebrovascular events (MACCE). Cl was independently associated with all-cause mortality during long-term observation $(p<0.01)$. Nocturnal BP rise had no significant predictive ability for all-cause mortality in elderly patients $(p=0.178)$.

Conclusions: Nocturnal BP rise contributed to greater cognitive impairment in elderly patients. Not nocturnal BP rise, but $\mathrm{Cl}$ could significantly increase all-cause mortality. Controlling BP based on ABPM is critical for preventing the progression of cognitive dysfunction.

Keywords: Ambulatory blood pressure monitoring, Blood pressure, Nocturnal blood pressure rise, Cognitive impairment

\footnotetext{
* Correspondence: Ihw19656@sina.com

'Department of Geriatrics, Beijing Friendship Hospital, Capital Medical University, Beijing 100050, PR China

${ }^{2}$ Department of Cardiology, Beijing Friendship Hospital, Capital Medical

University, No.95, Yongan Road, Xicheng District, Beijing 100050, PR China
}

(C) The Author(s). 2021 Open Access This article is licensed under a Creative Commons Attribution 4.0 International License, which permits use, sharing, adaptation, distribution and reproduction in any medium or format, as long as you give appropriate credit to the original author(s) and the source, provide a link to the Creative Commons licence, and indicate if changes were made. The images or other third party material in this article are included in the article's Creative Commons licence, unless indicated otherwise in a credit line to the material. If material is not included in the article's Creative Commons licence and your intended use is not permitted by statutory regulation or exceeds the permitted use, you will need to obtain permission directly from the copyright holder. To view a copy of this licence, visit http://creativecommons.org/licenses/by/4.0/. The Creative Commons Public Domain Dedication waiver (http://creativecommons.org/publicdomain/zero/1.0/) applies to the data made available in this article, unless otherwise stated in a credit line to the data. 


\section{Background}

Dementia affects approximately 50 million people worldwide and is expected to increase by nearly 9.9 million new cases each year. While Alzheimer's disease is the leading cause of cognitive impairment $(\mathrm{CI})$, vascular dementia is the second leading cause, with no effective therapies [1]. Cerebral small vessel disease is the most common pathology underlying vascular dementia, including lacunar infarcts (LCI) or white matter hyperintensities (WMH) [2]. Hypertension, which can affect brain structure and function, is known to be associated with CI. It is the major vascular risk factor for CI [3] . The associations between blood pressure (BP) and brain health are complex and are dependent on many factors such as age, hypertension chronicity, and hypertension variation. The elevated BP in midlife, particularly untreated hypertension, increases the risk for CI. Previous studies have either failed to find any association between hypertension and $\mathrm{CI}$ in the eighth, ninth and tenth decade of life or have reported high $\mathrm{BP}$ as having protective effect against CI [3].

Twenty-four-hour ambulatory BP monitoring (ABPM) offers much more information on variability and circadian BP pattern compared to office BP measurements and is superior in predicting future cardiovascular events [4]. Although the relationship between blood pressure variation (BPV) and CI has been addressed to some extent, previous studies have yielded conflicting results. McDonald and colleagues reported that daytime systolic variability was independently associated with greater cognitive decline in total CAMCOG and MMSE scores over a 5-year followup [5]. Kanemaru et al reported that increased short-term variability of daytime $\mathrm{BP}$ and high night-time systolic $\mathrm{BP}$ was associated with cognitive impairment as assessed by the Raven's Coloured Progressive Matrices Test (RCPM) [6]. Paganini-Hill et al assessed the patients aged 90+ years and found that mean nocturnal dips significantly differed between cognitively normal and impaired individuals, with cognitively normal participants having on average greater nocturnal dips. Nocturnal dips were also related to performance on select cognitive test scores $[7,8]$. The different study designs, measures of cognition, and population characteristics may explain this inconsistency.

Previous studies have reported on a cognitive impairment-mortality relationship and indicated that baseline cognitive impairment increases the risk of allcause mortality $[9,10]$. However, they have rarely studied the impacts of BPV on the association between cognitive impairment and mortality.

The present study assessed the relationship between BPV and CI in elderly patients with different levels of cognitive function assessed by MMSE and investigated the association of cognitive impairment on mortality.

\section{Methods}

\section{Participants}

This study included 583 inpatients, $\geq 65$ years of age, who received cognitive assessment and cerebral MRI at the Geriatric Medicine department of the Beijing Friendship Hospital between January 2014 and September 2019. The participants were followed up until March 2020. Among these subjects, 3 were excluded for chronic kidney disease, 57 were excluded for incomplete clinical information, 165 were excluded for the incomplete ambulatory blood pressure monitoring (ABPM), 37 were excluded for the incomplete MRI, and 16 were excluded for missed follow-up. Finally, 305 participants were included in this analysis to assess the effect of BPV and its risk factors on cognitive function in elderly subjects (Fig. 1).

The study was approved by the ethics committee of Beijing Friendship Hospital, Capital Medical University (code: 2018-P2-120-01) and was conducted in accordance with the Declaration of Helsinki.

Demographic characteristics, including years of education, medical history, clinical information, and concurrent medications, were collected.

Hypertension was defined as systolic blood pressure (SBP) $\geq 140 \mathrm{mmHg}$, diastolic blood pressure (DBP) $\geq 90$ $\mathrm{mmHg}$, or ongoing therapy for hypertension. Type-2 diabetes was defined as glycosylated hemoglobin (HbA1c) $\geq 6.5 \%$, a non-fasting plasma glucose concentration $\geq 200 \mathrm{mg} / \mathrm{dL}$, fasting plasma glucose concentration $\geq$ $126 \mathrm{mg} / \mathrm{dl}$, or if the patient was treated with oral hypoglycemic medications or insulin.

\section{Laboratory measurements}

Lipids, including total cholesterol (TC), triglyceride (TG), low-density lipoprotein cholesterol (LDL-C), and high-density lipoprotein cholesterol (HDL-C), were measured using standard methods of the central laboratory of the Beijing Friendship Hospital. Fasting glucose, glycosylated hemoglobin (HbA1c), liver and renal function, and albumin (ALB) were also measured. The CKD-EPI (the Chronic Kidney Disease Epidemiology Collaboration equation) calculated the estimated glomerular filtration rate (EGFR).

\section{Ambulatory blood pressure monitoring}

A validated ambulatory recorder (DMS-ABP, USA) and cuff were used on the non-dominant arm to perform ABPM. BP was measured at 30-min intervals for daytime (06.00-21.59 h) and 1-h intervals for night-time (22.00$05.59 \mathrm{~h}$ ). BP, including 24-h mean value, mean daytime value, and mean night-time value, were calculated from recorded measurements and used in data analyses.

The nocturnal BP fall (\%) was calculated using the following formula: (daytime SBP - night-time SBP)/ 


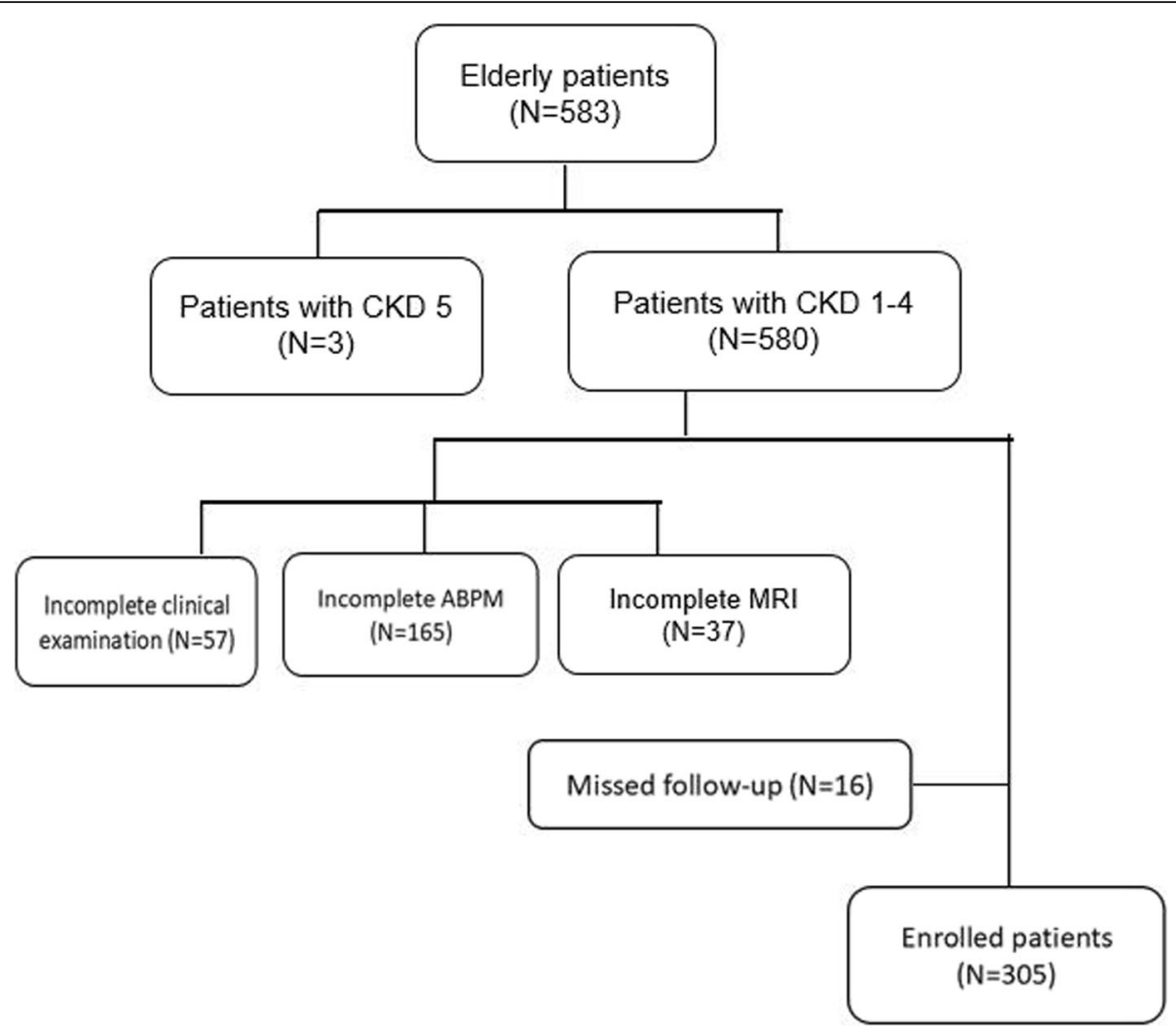

Fig. 1 Flow diagram of the study design

daytime SBP. We classified the nocturnal BP fall into the following three patterns: the dipper pattern if the nocturnal BP fall was > 10\%; the non-dipper pattern, if the nocturnal $\mathrm{BP}$ fall was between 0 and 10\%; and the rising pattern, if the nocturnal BP fall was $<0 \%$. Patients with an extreme dipper pattern (nocturnal BP fall $>20 \%$ ) were combined with those with the dipper pattern due to the limited number of cases $(n=6)$. Nocturnal hypertension was defined as a night-time SBP $\geq 120 \mathrm{mmHg}$ and/or night-time DBP $\geq 70 \mathrm{mmHg}$, based on the 2014 guidelines for the management of hypertension published by The Japanese Society of Hypertension.

\section{Magnetic resonance imaging protocol and assessments}

MRI images were acquired using a $3.0 \mathrm{~T}$ scanner (Siemens, Berlin, Germany) in the Radiology Department of our hospital. Sequences included T2-weighted imaging (T2WI), T1-weighted imaging (T1WI), diffusionweighted imaging (DWI), fluid-attenuated inversion recovery imaging (FLAIR), and susceptibility-weighted imaging (SWI). The main parameters were as follows: repetition time $(\mathrm{TR})=4500 \mathrm{~ms}$, echo time $(\mathrm{TE})=84 \mathrm{~ms}$, flip angle $(\mathrm{FA})=120^{\circ}$, matrix $=256 * 256$, field of view $(\mathrm{FOV})=220 * 220 \mathrm{~mm}^{2}$, slice thickness $=5 \mathrm{~mm}$, and slice gap $=1 \mathrm{~mm}$, number of slices $=24$.
White matter hyperintensities (WMHs) were identified as hyperintense areas in the periventricular and deep white matter on both T2WI and FLAIR. WMH was rated using the Fazekas scale on FLAIR images. Lacunar infarcts (LACs) were defined as small (diameter of 3-15 $\mathrm{mm}$ ), sharply demarcated hyperintense lesions on T2WI with corresponding foci of FLAIR low signal intensity and assessed in the basal ganglia, internal capsule, thalamus, brainstem, radiating crown, and semioval center. The number of WMHs and LCIs were calculated to assess the severity of cerebral small vessel disease. MRI assessments were performed by two experienced neuroradiologists who were blinded to the clinical information.

\section{Measurement of cognition}

Cognitive function was assessed by the Mini-Mental Status Examination (MMSE) with a total score 0-30. It included 11 items, categorized as: orientation (10 points), memory registration ( 3 points), attention and calculation (5 points), recall (3 points), language (10 points). A 27 point was proved to be an appropriate cutoff for cognitive impairment in a population with relatively high educational attainment [8].

Follow-up was performed by reviewing data from medical records or by telephone interviews. The primary 
outcome was all-cause mortality. Secondary endpoints were major adverse cardiac and cerebrovascular events (MACCE), including acute coronary syndrome (acute myocardial infarction or unstable angina pectoris), heart failure of NYHA III-IV, stroke/transient ischemic attacks (TIA), and cerebral hemorrhage.

\section{Statistical analysis}

All continuous variables were reported as mean \pm standard deviation $(\mathrm{M} \pm \mathrm{SD})$, and categorical variables were presented as counts and percentages. The KolmogorovSmirnov test was used for the normality assumption. Pearson's chi-squared test was used to investigate the categorical variables. For the analyses of continuous variables with normal distribution, a t-test was used to examine the differences between the normal cognition and impaired cognition patients. Kruskal-Wallis with post hoc Mann-Whitney U-test was used to analyze the continuous variables with non-normal distribution. Correlations between nocturnal BP fall and MMSE were evaluated using linear regression. Cox regression and Kaplan-Meier curves were used for survival analysis. All statistical analyses were performed using SPSS statistical software version 24.0 for Windows (SPSS Inc.), and a $p$ value $<0.05$ was considered statistically significant.

\section{Results}

\section{Baseline characteristics of participants}

A total of 305 participants with a mean age of 81 years were included in the study. The average years of education received was 14; $69 \%$ of participants were men; the average BMI was $24 ; 10.2 \%$ were smokers; $79 \%$ had hypertension, and $39.3 \%$ had diabetes. As shown in Table 1, 35.7\% of subjects were taking antiplatelet therapy, $46.5 \%$ were on a statin, $41.3 \%$ were on an ACEI or $\mathrm{ARB}, 43 \%$ were on a $\mathrm{CCB}$, and $30.2 \%$ were taking beta-

Table 1 Demographic characteristics of the study population

\begin{tabular}{|c|c|c|c|c|}
\hline & $\begin{array}{l}\text { All subjects } \\
(N=305)\end{array}$ & $\begin{array}{l}\mathrm{NCl} \text { group } \\
(n=175)\end{array}$ & $\begin{array}{l}\mathrm{Cl} \text { group } \\
(n=130)\end{array}$ & $p$-value \\
\hline Age, years & $80.6 \pm 7.6$ & $79.1 \pm 7.3$ & $82.5 \pm 7.7$ & $<0.001^{*}$ \\
\hline Male, n (\%) & $210(69)$ & $125(71.4)$ & $85(65.4)$ & 0.260 \\
\hline Education, years & $14.0 \pm 3.6$ & $14.8 \pm 3.0$ & $13.0 \pm 4.0$ & $<0.001^{*}$ \\
\hline $\mathrm{BMI}, \mathrm{kg} / \mathrm{m}^{2}$ & $24.3 \pm 3.6$ & $24.5 \pm 3.6$ & $23.9 \pm 3.6$ & 0.150 \\
\hline Smoking, n (\%) & $31(10.2)$ & $17(9.8)$ & $14(10.8)$ & 0.124 \\
\hline Hypertension, n (\%) & $242(79)$ & $136(77.7)$ & $106(81.5)$ & 0.415 \\
\hline Diabetes, n (\%) & $120(39.3)$ & $67(38.3)$ & $53(40.8)$ & 0.661 \\
\hline $\mathrm{FG}, \mathrm{mmol} / \mathrm{L}$ & $5.7 \pm 1.8$ & $5.5 \pm 1.3$ & $6.1 \pm 2.3$ & $0.016^{*}$ \\
\hline $\mathrm{HgB}$ & $130.1 \pm 15.7$ & $132.0 \pm 15.0$ & $127.6 \pm 16.3$ & $0.015^{*}$ \\
\hline ALB & $37.5 \pm 4.5$ & $38.5 \pm 4.3$ & $36.2 \pm 4.5$ & $<0.001^{*}$ \\
\hline $\mathrm{HbA} 1 \mathrm{c}, \%$ & $6.1 \pm 1.6$ & $5.9 \pm 1.0$ & $6.0 \pm 1.1$ & 0.168 \\
\hline $\mathrm{Cr}, \mathrm{mmol} / \mathrm{l}$ & 75.5 (25.2-205.4) & 73.5 (25.5-166.9) & 79.8 (34.8-205.4) & $0.021^{*}$ \\
\hline $\mathrm{eGFR}, \mathrm{ml} / \mathrm{min} / 1.73 \mathrm{~m}^{2}$ & $77.7(17.3-113.9)$ & $79.2(32.6-113.9)$ & $72.1(17.3-101.8)$ & $<0.001^{*}$ \\
\hline $\mathrm{TC}, \mathrm{mmol} / \mathrm{L}$ & $4.0 \pm 1.1$ & $4.0 \pm 0.9$ & $4.1 \pm 1.3$ & 0.541 \\
\hline $\mathrm{TG}, \mathrm{mg} / \mathrm{dL}$ & $1.3 \pm 0.8$ & $1.3 \pm 0.9$ & $1.2 \pm 0.7$ & 0.638 \\
\hline $\mathrm{HDL}-\mathrm{C}, \mathrm{mg} / \mathrm{dL}$ & $1.2 \pm 0.3$ & $1.2 \pm 0.3$ & $1.1 \pm 0.3$ & 0.634 \\
\hline LDL-C, mg/dL & $2.4 \pm 0.8$ & $2.4 \pm 0.7$ & $2.4 \pm 1.0$ & 0.478 \\
\hline Antiplatelet, n (\%) & $109(35.7)$ & $62(35.4)$ & $47(36.2)$ & 0.896 \\
\hline Statin, n (\%) & $151(46.5)$ & $93(53.1)$ & $58(44.6)$ & 0.141 \\
\hline ACEI/ARB, n (\%) & $126(41.3)$ & $72(41.1)$ & $54(41.5)$ & 0.945 \\
\hline CCB, n (\%) & $263(43)$ & $69(39.4)$ & $52(40)$ & 0.920 \\
\hline beta-blocker, n (\%) & $92(30.2)$ & $54(30.9)$ & $38(29.2)$ & 0.760 \\
\hline WMH & $2(0-3)$ & $1(0-3)$ & $2(0-3)$ & $<0.001^{*}$ \\
\hline $\mathrm{LCl}$ & $1.64 \pm 2.66$ & $1.52 \pm 0.71$ & $1.88 \pm 0.81$ & $0.019^{*}$ \\
\hline MMSE & $25.55 \pm 4.81$ & $28.66 \pm 1.05$ & $21.36 \pm 4.72$ & $<0.001^{*}$ \\
\hline
\end{tabular}

Values are mean $\pm \mathrm{SD}, \mathrm{n}$ (\%), or median (interquartile range). BMI Body mass index, FG Fasting glucose, $\mathrm{HgB}$ Hemoglobin, $A L B$ Albumin, $\mathrm{HbA} 1 \mathrm{C}$ Hemoglobin A1c, $\mathrm{Cr}$ Creatinine, eGFR Estimated Glomerular Filtration Rate, TC Total cholesterol, TG Triglycerides, HDL-C High-density lipoprotein, $L D L-C$ Low-density lipoprotein, $A C E I$ Angiotensin-converting enzyme inhibitor, $A R B$ Angiotensin receptor blocker, $C C B$ Calcium channel blocker, WMH White matter hyperintensities, $L C I$ Lacunar cerebral infarction, MMSE Mini-Mental Status Examination. ${ }^{*}: P<0.05$. 
blockers. The average HbA1c was $6.1 \%$. The average TC was $4.0 \mathrm{mmol} / \mathrm{l}$, TG was $1.3 \mathrm{mmol} / \mathrm{l}$, and LDL-C was 2.4 $\mathrm{mmol} / \mathrm{l}$.

Among 305 participants, $42.6 \%$ were identified as having CI with MMSE scores <27. Subjects with (CI group, $n=130$ ) and without CI (NCI group, $n=175$ ) were compared according to demographic and clinical characteristics and risk factors. As shown in Table 1, compared to NCI subjects, subjects with CI were significantly older (82.5 \pm 7.7 vs. $79.1 \pm 7.3$ years, $p<0.001)$, less educated $(13.0 \pm 4.0$ vs. $14.8 \pm 3.0$ years, $p<0.001)$, had higher fasting glucose $(6.1 \pm 2.3$ vs. $5.5 \pm 1.3 \mathrm{mmol} / \mathrm{l}, p=0.016)$, lower $\mathrm{HgB}(127.6 \pm 16.3$ vs. $132.0 \pm 15.0 \mathrm{~g} / \mathrm{dl}, p=0.015)$, significantly lower ALB $(36.2 \pm 4.5$ vs. $38.5 \pm 4.3 \mathrm{~g} / \mathrm{dl}, p<$ 0.001 ), significantly lower eGFR (72.1 vs. $79.2 \mathrm{ml} / \mathrm{min} /$ $1.73 \mathrm{~m}^{2}, p<0.001$ ), and more severe WMH ( 2 vs. $1, p<$ $0.01)$ and LCI ( $1.88 \pm 0.81$ vs. $1.52 \pm 0.71, p=0.019)$.

After an average follow-up of $2.03 \pm 1.45$ years, there were 35 all-cause deaths. Among them, 21 patients died due to pneumonia or abdominal infection, 4 due to cancer, 4 due to cardiovascular disease, and 6 due to other diseases. A total of 33 cases suffered from MACCE. Among them, 21 patients had stroke/TIA or cerebral hemorrhage, while there were 12 cases of acute coronary syndrome or acute heart failure.

\section{BP variation and cognitive impairment}

$\mathrm{BP}$ was reasonably controlled, with an average SBP of $127 \mathrm{mmHg}$ and DBP of $66 \mathrm{mmHg}$. According to ABPM, $13.1 \%$ of patients had a dipper pattern, $45.6 \%$ had nocturnal BP rise, and $41.3 \%$ had a non-dipper pattern. Compared with NCI patients, the patients with CI had significantly higher night-time SBP $(130.0 \pm 18.2 \mathrm{mmHg}$ vs. $123.9 \pm 15.1 \mathrm{mmHg}, p=0.002)$, and more patients had nocturnal BP rise $(52.3 \%$ vs. $40.6 \%, p=0.042)$. In contrast, there was no significant inter-group difference in DBP. The incidence of daytime SBP and nocturnal hypertension was higher in the patients with $\mathrm{CI}$ compared to those with normal cognition; the difference was not statistically significant (Table 2). Nocturnal BP rise had a positive correlation with MMSE $\left(\mathrm{R}^{2}=0.037, p=\right.$ 0.001) (Fig. 2A).

According to the Cox regression models, CI was independently associated with all-cause mortality during long-term observation (95\% CI, 6.001 (2.62-13.78), $p<$ 0.001 ), with $500 \%$ increase during follow-up (Fig. 2B). Nocturnal BP rise had no significant predictive value for all-cause mortality in elderly patients.

\section{Discussion}

Cognitive impairment (CI) is rampant among the elderly worldwide. This study enrolled 305 cases, with a mean SBP of $127.4 \mathrm{mmHg}$ and DBP of $66 \mathrm{mmHg}$. Among them, $130(42.6 \%)$ participants were identified with CI. These patients had worse nutrition and kidney function than individuals with normal cognition, which negatively affected their life quality and long-term prognosis. Hypertension is a major risk factor for cognitive dysfunction [11, 12], and the results of the Honolulu Asia Aging Study demonstrated a positive association between lower brain volume, neuritic plaques, and hypertension [12]. However, the relationship between BP variation and cognitive function remains unclear.

This study demonstrated that in elderly patients (mean age of 81 years), night-time SBP and nocturnal BP rise were positively correlated with $\mathrm{CI}$, even if the patients had normal BP. Mean BP and daytime BP showed no correlation. Nocturnal hypertension was not significantly higher in the CI group. These results are consistent with the findings of Manabu Kokubo and his colleagues [11], who reported that higher night-time SBP levels contributed to greater WMH volumes in elderly hypertensive patients. High nocturnal BP is also associated with an

Table 2 Ambulatory blood pressure monitoring parameters according to the cognitive function

\begin{tabular}{|c|c|c|c|c|}
\hline & All subjects $(n=305)$ & $\mathrm{NCl}(n=175)$ & $\mathrm{Cl}(n=130)$ & $p$-value \\
\hline Mean SBP, mmHg & $127.4 \pm 13.8$ & $126.1 \pm 12.5$ & $129.2 \pm 15.2$ & 0.055 \\
\hline Mean DBP, mmHg & $66 \pm 8.5$ & $65.9 \pm 8.1$ & $66.1 \pm 9.0$ & 0.887 \\
\hline $\mathrm{dSBP}, \mathrm{mmHg}$ & $127.1 \pm 14.1$ & $125.9 \pm 13.2$ & $128.7 \pm 15.1$ & 0.104 \\
\hline $\mathrm{dDBP}, \mathrm{mmHg}$ & $66.1 \pm 8.7$ & $66.1 \pm 8.3$ & $66.0 \pm 9.1$ & 0.908 \\
\hline $\mathrm{nSBP}, \mathrm{mmHg}$ & $126.5 \pm 16.7$ & $123.9 \pm 15.1$ & $130.0 \pm 18.2$ & $0.002^{*}$ \\
\hline $\mathrm{nDBP}, \mathrm{mmHg}$ & $64.4 \pm 9.9$ & $63.6 \pm 9.3$ & $65.5 \pm 10.6$ & 0.114 \\
\hline Nocturnal hypertension, n(\%) & $207(67.9)$ & $112(64)$ & $95(73.1)$ & 0.093 \\
\hline \multicolumn{5}{|l|}{ BP category } \\
\hline Dipper, n(\%) & $40(13.1)$ & $24(13.8)$ & $16(12.3)$ & 0.719 \\
\hline Non-dipper, n(\%) & $126(41.3)$ & $80(45.7)$ & $46(35.4)$ & 0.070 \\
\hline Rise, n(\%) & $139(45.6)$ & 71 (40.6) & 68 (52.3) & $0.042^{*}$ \\
\hline
\end{tabular}

SBP Systolic blood pressure, DBP Diastolic blood pressure, $C l$ Cognitive impairment, $N C l$ Non-cognitive impairment. * $p<0.05$. 

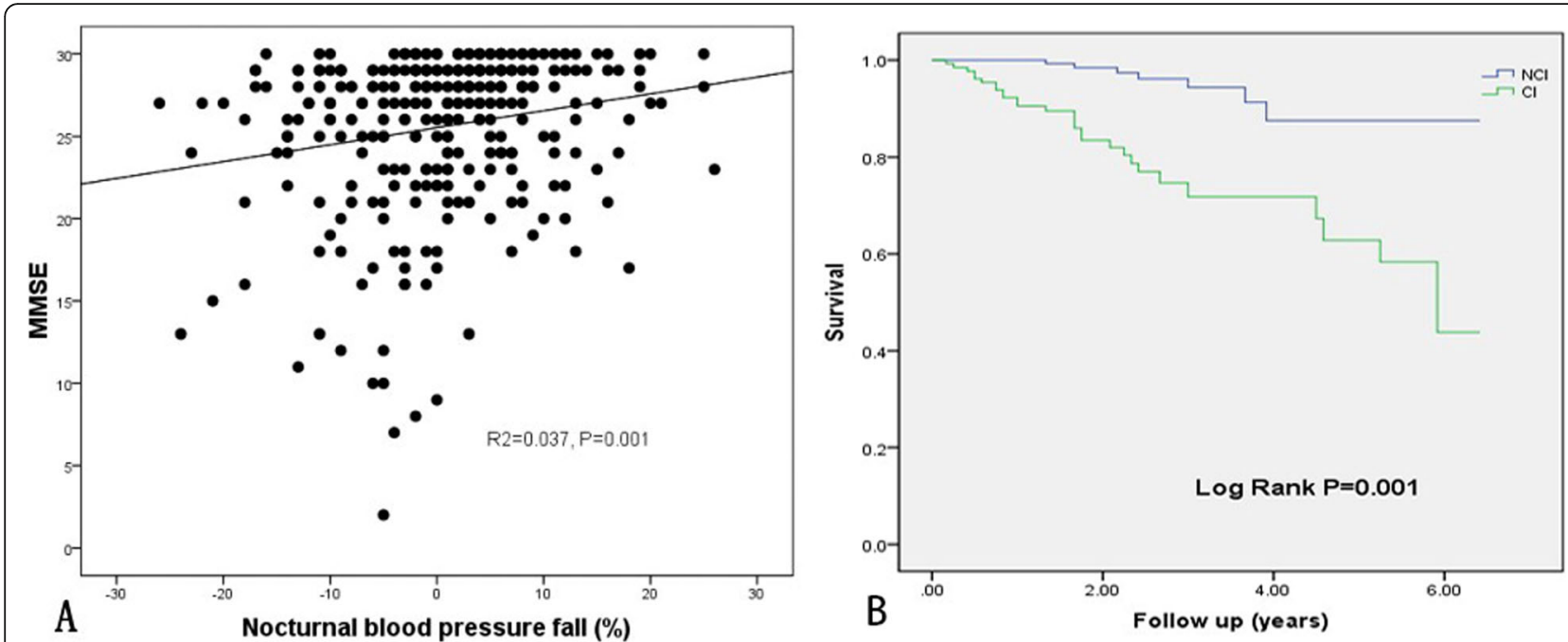

Fig. 2 Linear regression and K-M curve. A linear regression between nocturnal BP fall and MMSE. B K-M curve of cognitive impairment on the allcause mortality. Note: $\mathrm{NCl}$, non-cognitive impairment; Cl, cognitive impairment

increase in cardiovascular events [13] and the onset of chronic kidney disease [14] .

Despite enormous evidence supporting the role of atherosclerosis in the pathogenesis and progression of $\mathrm{CI}$, the mechanistic relationship between nocturnal BP and CI remains unknown. Following are some of the possible mechanisms: first, nocturnal BP rise decreased cerebral blood flow and was related to higher levels of insulin resistance markers in normotensive and untreated mildly hypertensive adults [15]. Second, non-dipping of nocturnal BP increased the markers of endothelial dysfunction and inflammation, which are proposed as candidate mechanisms of atherosclerosis [16]. Moreover, cerebral small vessel disease, including LCI and WMH, had a major role in the senile vascular CI $[2,17]$. This study also demonstrated that elderly patients with CI had more severe WMH and LCI than those without CI. Nocturnal $\mathrm{BP}$ rise contributed to greater $\mathrm{WMH}$ volumes but not LCI. This may be because WMH is more sensitive to the atherosclerotic risk factor than LCI.

We observed that nocturnal BP rise was associated with lower cognition, which could decrease MMSE by $2.9 \%$. Although several studies have suggested that the impact of hypertension on cognition is global, not all studies broadly investigated the distinct cognitive domains. Some studies reported attention and executive functioning domains as cognitive domains that are most vulnerable to hypertension [18] since cognitive processes rely heavily on the integrity of frontal and subcortical brain structures, which may be most vulnerable to the effects of hypertension. These findings supported our hypothesis that the deterioration of orientation, attention, calculation, and language that occurs with aging is a BP variation-related impairment [19]. Some studies reported that processing speed is the first cognitive domain to be impacted by white matter lesion burdens due to uncontrolled hypertension. Jacobs et al revealed that WMH location influenced the relation between WMH and executive functioning and that parietal WMH is a significant contributor to executive decline in MCI [20]. This study did not assess the WMH location in detail.

The present study showed that baseline CI measured by MMSE score was associated with an elevated risk of allcause mortality, which was consistent with previous studies $[17,18]$. Yet, the prognostic value of the nocturnal BP rise has not been established. The Ambulatory Blood Pressure Collaboration in Patients With Hypertension (ABC$\mathrm{H}$ ) examined this issue in a meta-analysis of 17,312 hypertensive patients (mean age of 50-70 years) who were followed up for 4-8 years. They found that the nondipping pattern could predict $33 \%$ of all-cause mortality and $57 \%$ of cardiovascular mortality after adjustment for 24-h SBP. Among the four different dipping subgroups, patients with nocturnal BP rise had the worst prognosis for cardiovascular events and all-cause mortality, and nocturnal BP rise was responsible for most of the nondipping pattern adverse prognosis [19]. This study showed that the patients with nocturnal BP rise had a higher incidence of cardiovascular disease than those without nocturnal BP rise $(15.1 \%$ vs. $7.2 \%, p=0.027)$. Still, nocturnal $\mathrm{BP}$ rise was not significantly associated with all-cause mortality. Perhaps nocturnal BP rise was more closely associated with cardiovascular events than mortality. The patients in this study were much older, and most of them died of infection or another disease, while only $11.4 \%$ died of cardiovascular events. So it is important to emphasize the importance of controlling BP using ABPM as an indicator to control cardiovascular events [21]. 
The present study has some limitations. First, as the present study was a cross-sectional study, the causeeffect relationship was unclear. Second, in addition to LCI and WMH, cerebral microbleeds are also a form of cerebral small vessel disease, which has been reported to be highly prevalent in memory clinic patients and those with Alzheimer's disease [22-24]. Third, the precise cause of cognitive impairment was not characterized in this study using molecular ligands or pathological confirmation.

\section{Conclusions}

The present study showed that nocturnal BP rise contributed to cognitive impairment in elderly patients. CI increased the mortality in the elderly, but the nocturnal BP rise did not. Further studies are required to determine whether lowering nocturnal BP should be targeted to prevent the progression of $\mathrm{CI}$.

\section{Abbreviations}

ABPM: Ambulatory blood pressure monitoring; MRI: Magnetic Resonance Imaging ; Cl: Cognitive impairment; NCl: Non-cognitive impairment group; LCl: Lacunar infarcts; WMH: White matter hyperintensities; BP: Blood pressure; BPV: Blood pressure variation; SBP: Systolic blood pressure; DBP: Diastolic blood pressure; BMI: Body mass index; FG: Fasting glucose;

HgB: Hemoglobin; ALB: Albumin; HbA1c: Hemoglobin A1c; Cr: Creatinine; eGFR: Estimated glomerular filtration rate; TC: Total cholesterol;

TG: Triglycerides; HDL-C: high-density lipoprotein; LDL-C: Low-density lipoprotein; ACEl: Angiotensin-converting enzyme inhibitor; ARB: Angiotensin receptor blocker; CCB: Calcium channel blocker; MoCA: Montreal Cognitive Assessment; MMSE: Mini-Mental Status Examination; TIA: Transient ischemic attacks

\section{Acknowledgments}

We are grateful to all participating people and their families. We acknowledge all staffs for their great contributions to the success of the program.

\section{Authors' contributions}

Conceived the study protocol and design: XYL and LHW. Acquisition of data: $X Y L$ and WS. Data analysis and interpretation: SY and FF. Statistical analysis: $X Y L$ and ZDQ. Drafted the article: XYL. Critically revised the article: XYL, SY, ZDQ, LHW. All authors read and approved the final manuscript.

\section{Funding}

This study was supported by the Beijing Municipal Administration of Hospitals Clinical Medicine Development of Special Funding Support (Code: ZYLX201838). There were no significant interactions between the researchers and the funding body regarding the study design; data collection, analysis, and manuscript writing.

\section{Availability of data and materials}

The datasets used during the current study are available from the corresponding author on reasonable request.

\section{Declarations}

\section{Ethics approval and consent to participate}

The study protocol was approved by the Ethics Committee for Clinical Research of Beijing Friendship Hospital before the performance of the analyses (code: 2018-P2-120-01). This was a retrospective study, and only medical records were analyzed. All procedures involving human participants were performed in accordance with the ethical standards of the Ethics Committee for Clinical Research of Beijing Friendship Hospital and with the Declaration of Helsinki and its later amendments. The need to obtain participants' consent was waived by the ethics committee.
Consent for publication

Not applicable.

\section{Competing interests}

The authors declare that they have no competing interests.

Received: 3 November 2020 Accepted: 30 July 2021

Published online: 11 August 2021

\section{References}

1. Santisteban MM, ladecola C. Hypertension, dietary salt and cognitive impairment. J Cereb Blood Flow Metab. 2018;38(12):2112-28.

2. Li Q, Yang Y, Reis C, Tao T, Li W, Li X, et al. Cerebral small vessel disease. Cell Transplant. 2018:27(12):1711-22.

3. Walker KA, Sharrett AR, Wu A, Schneider ALC, Albert M, Lutsey PL, et al. Association of Midlife to late-life blood pressure patterns with incident dementia. JAMA. 2019;322(6):535-45.

4. Staessen JA, Thijs L, Fagard R, O'Brien ET, Clement D, de Leeuw PW, et al. Predicting cardiovascular risk using conventional vs. ambulatory blood pressure in older patients with systolic hypertension. JAMA. 1999;282:53946.

5. McDonald C, Pearce MS, Kerr SR, Newton JL. Blood pressure variability and cognitive decline in older people: a 5-year longitudinal study. J Hypertens. 2017;35(1):140-7.

6. Kanemaru A, Kanemaru K, Kuwajima I. The effects of short-term blood pressure variability and nighttime blood pressure levels on cognitive function. Hypertens Res. 2001;24(1):19-24.

7. Paganini-Hill A, Bryant N, Corrada MM, Greenia DE, Fletcher E, Singh B, et al. Blood Pressure Circadian Variation, Cognition and Brain Imaging in 90+ Year-Olds. Front Aging Neurosci. 2019;17(11):54.

8. O'Bryant SE, Humphreys JD, Smith GE, Ivnik RJ, Graff-Radford NR, Petersen $\mathrm{RC}$, et al. Detecting dementia with the mini-mental state examination in highly educated individuals. Arch Neurol. 2008;65(7):963-7.

9. An R, Liu G. Cognitive impairment and mortality among the oldest-old Chinese. Int J Geriatr Psychiatry. 2016;31:1345-53.

10. Gao S, Jin Y, Unverzagt FW, Cheng Y, Su L, Wang C, et al. Cognitive function, body mass index and mortality in a rural elderly Chinese cohort. Arch Public Health. 2014;72:9

11. Kokubo M, Shimizu A, Mitsui T, Miyagi M, Nomoto K, Murohara T, et al. Impact of night-time blood pressure on cerebral white matter hyperintensity in elderly hypertensive patients. Geriatr Gerontol Int. 2015;1: 59-65.

12. ladecola C, Gottesman RF. Neurovascular and cognitive dysfunction in hypertension. Circ Res. 2019;124(7):1025-44.

13. Kario K, Kanegae H, Tomitani N, Okawara Y, Fujiwara T, Yano Y, et al. Nighttime blood pressure measured by home blood pressure monitoring as an independent predictor of cardiovascular events in general practice. Hypertension. 2019;73(6):1240-8.

14. Li Y, Deng Q, Li H, Ma X, Zhang J, Peng H, et al. Prognostic value of nighttime blood pressure load in Chinese patients with nondialysis chronic kidney disease. J Clin Hypertens. 2017;19(9):890-8.

15. Gkaliagkousi E, Anyfanti P, Lazaridis A, Triantafyllou A, Vamvakis A, Koletsos $\mathrm{N}$, et al. Clinical impact of dipping and nocturnal blood pressure patterns in newly diagnosed, never-treated patients with essential hypertension. J Am Soc Hypertens. 2018;12(12):850-7

16. von Känel R, Jain S, Mills PJ, Nelesen RA, Adler KA, Hong S, et al. Relation of nocturnal blood pressure dipping to cellular adhesion, inflammation and hemostasis. J Hypertens. 2004;22(11):2087-93.

17. Chen X, Wang J, Shan Y, Cai W, Liu S, Hu M, et al. Cerebral small vessel disease: neuroimaging markers and clinical implication. J Neurol. 2019; 266(10):2347-62.

18. Goldstein FC, Hajjar IM, Dunn CB, Levey Al, Wharton W. The relationship between cognitive functioning and the JNC-8 guidelines for hypertension in older adults. J Gerontol A Biol Sci Med Sci. 2017;72(1):121-6.

19. Waldron-Perrine B, Kisser JE, Brody A, Haacke EM, Dawood R, Millis S, et al. $M R I$ and neuropsychological correlates in African Americans with hypertension and left ventricular hypertrophy. Am J Hypertens. 2018;31(8): 865-8.

20. Jacobs HI, Visser PJ, Van Boxtel MP, Frisoni GB, Tsolaki M, Papapostolou P, et al. Association between white matter hyperintensities and executive 
decline in mild cognitive impairment is network dependent. Neurobiol Aging. 2012;33(1):23

21. Sakhuja S, Booth JN, Lloyd-Jones DM, Lewis CE, Thomas SJ, Schwartz JE, et al. Health behaviors, nocturnal hypertension, and non-dipping blood pressure: the coronary artery risk development in young adults and Jackson heart study. Am J Hypertens. 2019;32(8):759-68.

22. Zhang J, Liu L, Sun H, Li M, Li Y, Zhao J, et al. Cerebral microbleeds are associated with mild cognitive impairment in patients with hypertension. J Am Heart Assoc. 2018;7(11):008453.

23. Zhou H, Yang J, Xie P, Dong Y, You Y, Liu J. Cerebral microbleeds, cognitive impairment, and MRI in patients with diabetes mellitus. Clin Chim Acta. 2017:470:14-9.

24. Vasquez BP, Zakzanis KK. The neuropsychological profile of vascular cognitive impairment not demented: a meta-analysis. J Neuropsychol. 2015; 9(1):109-36.

\section{Publisher's Note}

Springer Nature remains neutral with regard to jurisdictional claims in published maps and institutional affiliations.

Ready to submit your research? Choose BMC and benefit from:

- fast, convenient online submission

- thorough peer review by experienced researchers in your field

- rapid publication on acceptance

- support for research data, including large and complex data types

- gold Open Access which fosters wider collaboration and increased citations

- maximum visibility for your research: over $100 \mathrm{M}$ website views per year

At $B M C$, research is always in progress.

Learn more biomedcentral.com/submissions 